\title{
Development of Oral Fast-Disintegrating Levothyroxine Films for Management of Hypothyroidism in Pediatrics
}

\author{
He Zhang*, Mei-Gui Han, Yun Wang, Jie Zhang, Zi-Ming Han and Shu-Jun Li \\ Department of Pediatrics, The First Affiliated Hospital of Xinxiang Medical University, Xinxiang 453100, China
}

${ }^{*}$ For correspondence: Email: zhanghe094@gmail.com; Tel/Fax: 0086-373-4402514

Received: 9 April 2015

Revised accepted: 31 August 2015

\begin{abstract}
Purpose: To develop fast disintegrating films of levothyroxine (LVX) using hydrophilic hydroxypropyl methylcellulose (HPMC), croscarmellose sodium (CCS) as superdisintegrant, and propylene glycol (PG) as a plasticizer.

Methods: Fast-disintegrating films were formulated by solvent casting evaporation method using 3factor, 2-level full factorial design. The films were evaluated for disintegration time, in vitro drug release, physical appearance, thickness, weight variation, folding endurance, drug content uniformity, The effect of concentration of dependent variables (HPMC, CCS and PG) on disintegration time and in vitro drug release was studied.

Results: Suitable fast-disintegrating films were obtained using HPMC, CCS and PG. The minimum disintegration time (DT) was $15 \mathrm{~s}$ and maximum drug release (DR) in $1 \mathrm{~h}$ was $97.56 \%$. All independent variables selected for the study were statistically significant $(p<0.5)$. Increase in the concentrations of independent variables increased DR and DT.

Conclusion: The findings of this study indicate that the developed fast-disintegrating film is suitable for levothyroxine in the management of hypothyroidism in pediatrics.
\end{abstract}

Keywords: Hypothyroidism, Superdisintegrant, Fast-disintegrating, Levothyroxine, Oral films, Hydroxypropyl methylcellulose, Croscarmelose sodium, Propylene glycol

\begin{abstract}
Tropical Journal of Pharmaceutical Research is indexed by Science Citation Index (SciSearch), Scopus, International Pharmaceutical Abstract, Chemical Abstracts, Embase, Index Copernicus, EBSCO, African Index Medicus, JournalSeek, Journal Citation Reports/Science Edition, Directory of Open Access Journals (DOAJ), African Journal Online, Bioline International, Open-J-Gate and Pharmacy Abstracts
\end{abstract}

\section{INTRODUCTION}

Hypothyroidism, often referred to as underactive thyroid, low thyroid and sometimes, hypothyreosis, is a common endocrine disorder in which the thyroid gland does not produce enough thyroid hormone [1,2]. It is associated with tiredness, poor ability to tolerate cold, and weight gain. In children, hypothyroidism leads to delay in growth and intellectual development, known as cretinism in severe cases [3]. The age of symptom onset is unpredictable in a child who has thyroid dysgenesis with a hypoplastic and or ectopic thyroid gland because initial increases in Thyroid stimulating harmone (TSH) may be able to initially overcome the relative insufficiency of the thyroid gland. Newborn children with hypothyroidism may have normal birth weight and height (although the head may be larger than expected and the posterior fontanelle may be open). Some may have drowsiness, decreased muscle tone, a hoarse-sounding cry, feeding difficulties, constipation, an enlarged tongue, umbilical hernia, dry skin, decreased body temperature and jaundice $[4,5]$.

Levothyroxine sodium (LVX) is used for the treatment or prevention of various types of deficiency such as hypothyroidism, cretinism, non-toxic goitre, myxoedema and coma in 
newborn, infants and children [6]. LVX is also effective in the suppression of pituitary thyroid stimulating harmone (TSH) secretion in the treatment or prevention of various types of euthyroid goiters. LVX tablets are available in the market for the treatment of hypothyroidism for pediatrics. [7]. One of the greatest challenges in pediatric pharmacology has been optimization of oral drug delivery. In a recent study, $54 \%$ of children between the ages of 6 and 11 years told study investigators that they were unable to easily swallow a tablet $[8,9]$.

Oral fast-disintegrating film containing active drug molecule is a delivery technology for the oral delivery of drugs as an alternative to conventional dosage forms such as tablets, capsules, syrups and other formulations, for pediatric and geriatric use. Oral fast disintegrating films are easy to administer and provide better patient compliance in the elderly, pediatric, mentally retarded, nauseated and uncooperative patients [10]. Thus, the aim of the present study was to develop oral fastdisintegrating films of LVX for the management of hypothyroidism in pediatrics for improved patient compliance.

\section{EXPERIMENTAL}

\section{Materials}

Levothyroxine (LVX) was purchased from Baoji Guokang Bio-Technology Co., Ltd. (Baoji, Shaanxi, China), hydroxypropyl methylcellulose (HPMC) and croscarmellose sodium (CCS) was purchased from Sigma Aldrich, USA. Propylene glycol and sorbitol were purchased from Shanghai Chemical Co. (Shanghai, China).

\section{Preparation of fast disintegrating films}

Fast-disintegrating film of LVX was prepared by solvent-casting evaporation method [11]. The composition of the formulation is presented in Table 2. The required quantity of polymer (HPMC) and plasticizer (propylene glycol) was dissolved in double distilled water. This polymeric dispersion was stirred for $1 \mathrm{~h}$ using magnetic stirrer at $500 \mathrm{rpm}$ and kept aside to remove all the air bubbles entrapped. In another beaker the aqueous solution was prepared by dissolving specified quantities of LVX, CCS and sorbitol in specific proportion in the mixture of distilled water and alcohol. Polymeric dispersion was added to solution containing LVX and stirred for $1 \mathrm{~h}$. After removal of air bubbles, the polymeric solution containing drug was casted into glass petridish of specified dimension $\left(30 \mathrm{~cm}^{2}\right)$ and dried in the vacuum oven at $28{ }^{\circ} \mathrm{C}$ for $24 \mathrm{~h}$. The film was carefully removed from the Petri dish, observed for any imperfections and cut into circular pieces $\left(5 \mathrm{~cm}^{2}\right)$.

Table 1: Variable and three levels

\begin{tabular}{lcc}
\hline Variable & $\begin{array}{c}\text { Low level (- } \\
1)\end{array}$ & $\begin{array}{c}\text { High level } \\
(+1)\end{array}$ \\
\hline Independent & & \\
A= HPMC Conc. & 30 & 40 \\
B= CCS Conc. & 2 & 4 \\
C= PG Conc. & 10 & 15 \\
Dependent & & \\
Y1=DT & & \\
Y2=\%DR & & \\
\hline
\end{tabular}

\section{$2^{3}$ factorial design for formulation of films}

Statistical analysis of the experimental work was carried out using Design Expert 6.0.8 portable software. A 3-factor, 2-level full factorial design was used to derive a second order polynomial equation. Concentration of HPMC (A), CCS (B) and Propylene glycol (C) were selected as a independent variables while disintegration time (Y1) and in vitro drug release (Y2) were selected as a dependent variables. Variables and three levels are presented in Table 1.

Table 2: Formulation of LVX fast disintegrating films using $2^{3}$ Factorial Design

\begin{tabular}{lccccc}
\hline Batch & \multicolumn{3}{c}{ Factor } & Response \\
& $\boldsymbol{A}$ & $\boldsymbol{B}$ & $\boldsymbol{C}$ & $\boldsymbol{Y 1}$ & $\boldsymbol{Y} 2$ \\
\cline { 2 - 6 } F1 & +1 & +1 & +1 & 15 & 97.56 \\
F2 & +1 & -1 & +1 & 52 & 85.29 \\
F3 & +1 & -1 & -1 & 45 & 80.78 \\
F4 & -1 & +1 & +1 & 25 & 88.32 \\
F5 & -1 & +1 & -1 & 18 & 92.3 \\
F6 & +1 & +1 & -1 & 20 & 90.11 \\
F7 & -1 & -1 & +1 & 55 & 82.35 \\
F8 & -1 & -1 & -1 & 60 & 78.25 \\
\hline
\end{tabular}

\section{Physical evaluation of films}

Smoothness, color, clarity, transparency of oral films was examined visually. Thickness of film formulations were evaluated by using micrometer screw gauze. The thickness of 5 film pieces was taken and the mean was taken. The surface $\mathrm{pH}$ of the film was determined by placing the film in petridish, slightly wet with the help of distilled water. The $\mathrm{pH}$ was noted by bringing the surface of the film in contact with $\mathrm{pH}$ meter electrode for one minute. Folding endurance test was performed by repeatedly folding the film at the same place until it broke. The number of times the film could be folded at the same place without breaking or cracking gave the value of folding endurance [12]. 


\section{Content uniformity test}

Each film was soaked and dissolved in $20 \mathrm{ml}$ of dichloromethane and resulting solution was filtered to remove undissolved residue. Aliquots were prepared and measured for drug content at $297 \mathrm{~nm}$ using UV spectrophotometer (Schimadzu 1700) [13].

\section{In vitro disintegration time (DT) test}

In vitro DT of each film was determined in $\mathrm{pH} 6.8$ phosphate buffer. Approximately $25 \mathrm{ml}$ of 6.8 phosphate buffer was placed in a Petri dish. The film $\left(1 \mathrm{~cm}^{2}\right)$ to be evaluated for DT was placed in this petri plate and time taken by each film to complete disintegrate was noted and considered as DT [13].

\section{Ex vivo permeation studies}

Ex-vivo permeation studies were carried out through porcine oral mucosa using specially designed glass diffusion cell. All animal procedures were conducted in accordance with all appropriate regulatory standards according to the protocol approved by the Institutional Animal Care and Use Committee of the Xinxiang Medical University (approval no. Xing/col/FA2145). The animal studies were performed as per the international CPCSEA guidelines. Porcine oral mucosa was soaked previously for $24 \mathrm{~h}$ in $\mathrm{pH} 6.8$ phosphate buffer $[10,13]$. This oral mucosa was stretched around one end of the diffusion cell. The working surface area of the membrane was $3.5 \mathrm{~cm}^{2}$. Donor compartment (tube) was adjusted into a glass beaker containing $\mathrm{pH} 6.8$ phosphate buffer (receptor compartment) in such a way that, the oral mucosa just touched the receptor medium. 1 $\mathrm{cm}^{2}$ weighed buccal film was placed on the oral mucosa. The receptor medium was maintained at $37 \pm 0.5^{\circ} \mathrm{C}$ and stirred at $50 \mathrm{rpm} .5 \mathrm{ml}$ aliquots of samples were withdrawn from the receptor medium at predetermined time intervals and replaced with equal volume of fresh buffer to maintain the sink condition. Samples were analysed with UV-Spectrophotometer at $297 \mathrm{~nm}$ and drug release was calculated.

\section{Data analysis}

Statistical analysis of the experimental work was carried out using Design Expert 6.0.8 portable software. A 3-factor, 2-level full factorial design was used to derive a second order polynomial equation. The contour plots were constructed to identify the effects of independent variables on dependent variables.

\section{RESULTS}

\section{Physical characteristics of films}

LVX fast disintegrating films were prepared by solvent casting evaporation technique were transparent, smooth, soft, and colorless in nature. Drug content uniformity of was in the range of 97.59 to $99.58 \%$ while the while thickness of the film was in the range of 0.17 to $0.30 \mathrm{~mm}$. Folding endurance of the film ranged from 160 to 200 , and $\mathrm{pH}$ of the film was 6.63 to 7.13. All the physical parameters are summarized in Table 3.

\section{DISCUSSION}

Patient compliance, convenience of administration of the dosage form and safety are the major factors considered during the development of the dosage form for pediatric patients suffered from disorders of the endocrine system like hypothyroidism, goiter etc [14]. Commercially available dosage forms for pediatrics like tablets, capsules, oral liquid medications have lot of disadvantages e.g. patient compliance, inability to swallow a dosage form [14]. So in order to avoid such drawbacks fast disintegrating films offer great potential for rapid and convenient drug delivery technology for the pediatric patients.

Table 3: Physical characteristics of films

\begin{tabular}{lccccc}
\hline Batch & $\begin{array}{c}\text { Drug content } \\
\text { (\%) }\end{array}$ & $\begin{array}{c}\text { Folding } \\
\text { endurance }\end{array}$ & $\begin{array}{c}\text { Thickness } \\
\text { (mm) }\end{array}$ & $\mathbf{p H}$ & Film nature \\
\hline F1 & 98.90 & 200 & 0.17 & 6.70 & Transparent \\
F2 & 99.20 & 175 & 0.20 & 7.13 & Smooth \\
F3 & 98.50 & 185 & 0.22 & 6.90 & Smooth \\
F4 & 99.56 & 145 & 0.25 & 6.87 & Soft \\
F5 & 97.59 & 220 & 0.24 & 6.73 & Soft \\
F6 & 99.58 & 160 & 0.30 & 6.90 & Smooth \\
F7 & 98.54 & 180 & 0.23 & 6.63 & Transparent \\
F8 & 97.80 & 165 & 0.21 & 6.65 & Transparent \\
\hline
\end{tabular}


Such fast disintegrating films are more acceptable to patients with hypothyroidism, goiter, dysphagia in pediatric patients. These films are mainly consisting of hydrophlic polymer, superdisintegrants, plasticizers, sweeteners etc which gets dissolved in mouth within seconds. In this experiment the minimum DT of 15 seconds was successfully achieved by using CCS as a superdisintegrant. These films are to be placed on the tongue for oral absorption, under the tongue for sublingual absorption. Such route bypass gut absorption and delivery into the hepatic portal system, thus avoiding the first pass metabolism and increasing the bioavailability[20].The first FDA approved oral disintegrating film is ondendetron (Zuplenz®) which was approved on 2010. Also several films of rizatriptan, rotavirus vaccine and levocetrizine have been under development. These developments and FDA approval clearly indicates the importance of these films in pediatrics and other type of patients who have problem of swallowing and patient compliance[15].

In vitro disintegration time (DT) was determined in $6.8 \mathrm{pH}$ phosphate buffer. Generally the $\mathrm{pH}$ of saliva ranges from $\mathrm{pH} 6.2-7.4$. DT was 15 to 60 $\mathrm{s}$ as shown in Table 4.

From the results presented in Table 4 it clearly indicated that the formulated films had fast disintegrating nature at saliva $\mathrm{pH}$. The polynomial equation obtained for DT $(\mathrm{Y} 1)$ is given in Eq 1.

$\mathrm{Y} 1=+36.25-3.25 \mathrm{~A}-16.75 \mathrm{~B}+0.50 \mathrm{C}+0.000 \mathrm{BC} . .(1)$

where $\mathrm{Y} 1$ is the DT, $\mathrm{A}$ is HPMC concentration, $\mathrm{B}$ is CCS concentration and $C$ is propylene glycol concentration.
Table 4: DT and $\%$ DR at $t=1 \mathrm{~h}$

\begin{tabular}{lll}
\hline Batch & DT $(\mathbf{s})$ & DR $(\%)$ \\
\hline F1 & 15 & 97.56 \\
F2 & 52 & 85.29 \\
F3 & 45 & 80.78 \\
F4 & 25 & 88.32 \\
F5 & 18 & 92.30 \\
F6 & 20 & 90.11 \\
F7 & 55 & 82.35 \\
F8 & 60 & 78.25 \\
\hline
\end{tabular}

The model $\mathrm{F}$-value 0.0160 indicates the model is significant $(p<0.05)$. A positive value in above equation represents the synergistic effect of the independent variable and a negative value represents the antagonistic effect [16]. The suggested model for the $\mathrm{Y} 1$ was found to be $2 \mathrm{FI}$ as shown in Table 5.

The value of correlation coefficient $\left(R^{2}\right)$ for the response $\mathrm{Y} 1$ was 0.9650 which indicates good fit for the $2 \mathrm{FI}$ model. The $p$-value for the $\mathrm{Y} 1$ model was 0.0160 which clearly indicates the model is statistically significant, viz, the three independent variables selected for all the factors: $\mathrm{A}$ ( $p=$ $0.0045), \mathrm{B}(p=0.0030), \mathrm{C}(p=0.0035)$. The data are shown in Table 6.

The polymer used for the preparation of film had good film forming property with non-toxic, nonirritant, good wetting properties [10]. This polymer played important role in imparting necessary mechanical properties to the film. It also influenced the DT of the film. As can be seen from contour plot Figure $1(\mathrm{~A})$ as the concentration of HPMC increases from 30 to 40 $\%$ the DT of the patches was found to be increased. Increase in the concentration of HPMC had a negative effect on DT of films.

Table 5: Summary of results of regression analysis for responses $\mathrm{Y} 1$ and $\mathrm{Y} 2$

\begin{tabular}{|c|c|c|c|c|c|c|}
\hline Model & $\mathbf{R}^{2}$ & Adjusted $\mathrm{R}^{2}$ & Predicted $\mathbf{R}^{2}$ & Std. Dev & Press & Remarks \\
\hline \multicolumn{7}{|c|}{ Response Y1 } \\
\hline Linear & 0.8260 & 0.8035 & 0.6514 & 7.36 & 510.20 & \\
\hline $2 \mathrm{FI}$ & 0.9650 & 0.9184 & 0.7512 & 5.31 & 600.89 & suggested \\
\hline Quadratic & 0.9265 & 0.9072 & 0.7825 & 0.45 & 550.30 & \\
\hline Cubic & 0.9120 & 0.8966 & 0.5912 & 0.49 & 462.20 & \\
\hline \multicolumn{7}{|c|}{ Response Y2 } \\
\hline Linear & 0.6599 & 0.6090 & 0.3563 & 3.75 & 120.73 & \\
\hline $2 \mathrm{FI}$ & 0.9353 & 0.8491 & 0.5402 & 2.50 & 133.65 & suggested \\
\hline Quadratic & 0.9020 & 0.8871 & 0.8598 & 4.90 & 112.30 & ........... \\
\hline Cubic & 0.9114 & 0.9025 & 0.8790 & 6.50 & 125.36 & $\ldots \ldots \ldots$ \\
\hline $\begin{array}{l}\text { Regression e } \\
Y 1=+36.25-3 \\
Y 2=+86.87+\end{array}$ & $\begin{array}{l}\text { ns of the } \\
6.75 B+0 . \\
5.20 B+1 .\end{array}$ & $\begin{array}{l}\text { d models } \\
+0.000 B C \\
+1.48 A C\end{array}$ & & & & \\
\hline
\end{tabular}


Table 6: ANOVA of models for $Y 1$ and $Y 2$

\begin{tabular}{llllll}
\hline Source & DF & Sum of squares & Mean square & $\boldsymbol{F}$-value & $\boldsymbol{P}$-value \\
\hline Model for $\boldsymbol{Y 1}$ & 4 & 2331 & 582.75 & 20.69 & 0.0160 \\
A & 1 & 84.50 & 84.50 & 3.00 & 0.0045 \\
B & 1 & 2244.50 & 2244.50 & 79.69 & 0.0030 \\
C & 1 & 2.00 & 2.00 & 0.071 & 0.0035 \\
BC & 1 & 0.000 & 0.000 & 0.000 & 1.000 \\
Model for Y2 & 4 & 271.89 & 67.97 & 10.85 & 0.0395 \\
A & 1 & 19.59 & 19.59 & 3.13 & 0.0351 \\
B & 1 & 216.53 & 216.53 & 34.56 & 0.0098 \\
C & 1 & 18.24 & 18.24 & 2.91 & 0.02865 \\
AC & 1 & 17.52 & 17.52 & 2.80 & 0.1930 \\
\hline
\end{tabular}

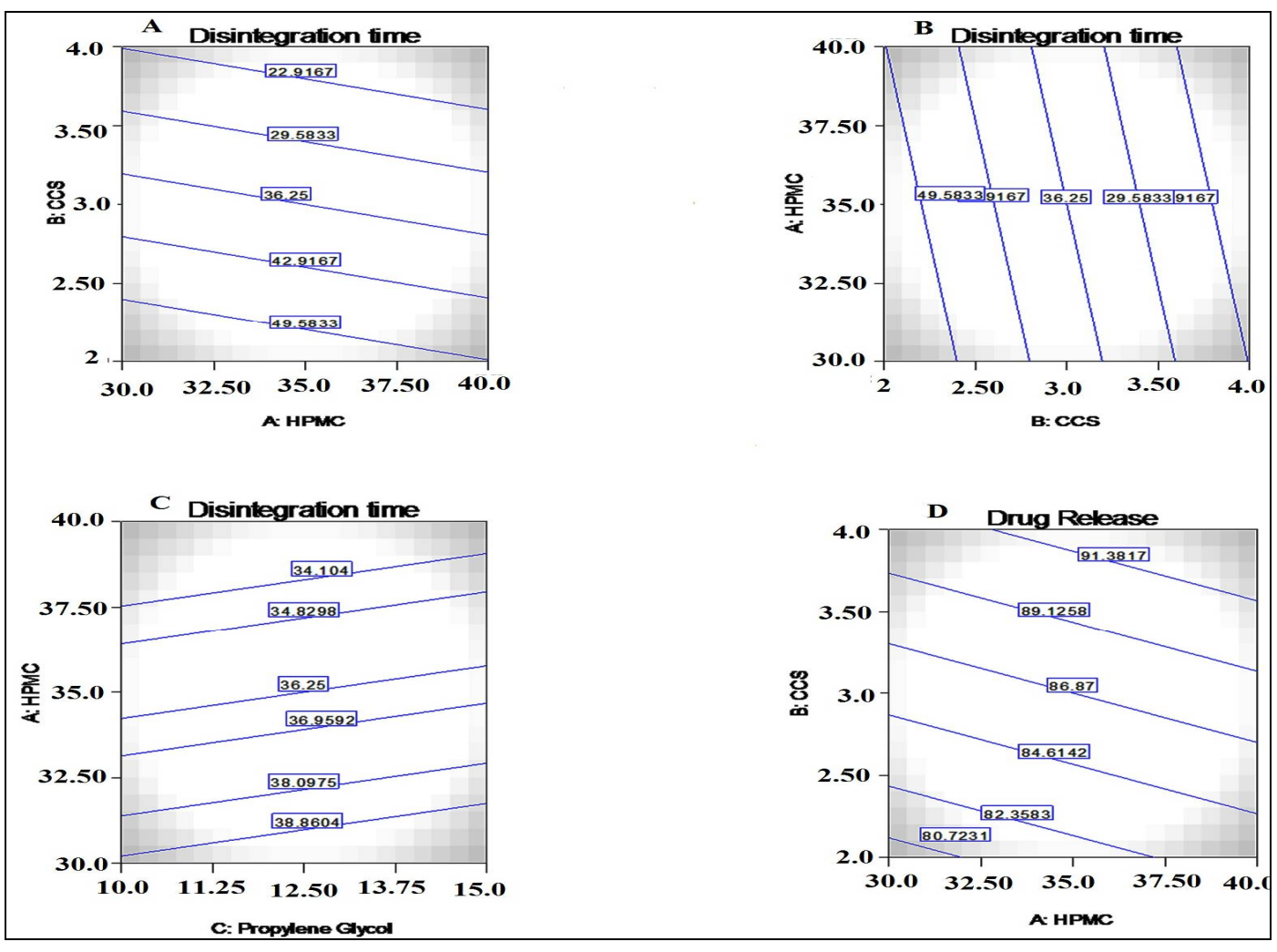

Figure 1: (A):Effect of HPMC on DT of film; (B): Effect of CCS on DT of film; (C): Effect of PG on DT; (D): Effect of HPMC on DR from the films

From above polynomial equation it was also clear that the HPMC concentration (A) has negative effect on DT as coefficient of $A$ is -3.25 . The possible reason for such increase in DT was the formation of more dense polymeric dispersion that led to resist in disintegration of the formed film [17].

CCS was used as a superdisintegrant in films to minimize the DT of the oral films containing the LVX. From the contour plot in Figure 1(B), it is clear that as the concentration of CCS increased the DT get decreased. This effect was statistically significant B $(p=0.0030)$. The minimum DT was $15 \mathrm{~s}$ at concentration of $4 \%$ CCS. CCS has been already utilized in tablets, capsules and films to adjust the DT of the formulation. CCS is having great swelling and minimum gelling capacity at low concentration ranging from 2.0 to $6.0 \%$. Above $8.0 \%$, it shows higher gelling property with increased viscosity that result into increase in DT. So in this study the concentration was maintained at 2.0 and 4.0 $\%$. CCS is a cross linked polymer of carboxymethyl cellulose sodium. Cross linking makes it insoluble, hydrophilic, highly absorbent material, resulting in excellent swelling properties and its unique fibrous nature gives it excellent water wicking capabilities [18].

Propylene glycol was used as a plasticizer to impart strength to the oral film. Also it was responsible for increasing the flexibility, preventing brittleness or breakage of the film. In 
this film development the PG was used in two levels (10 and $15 \%$ ). The PG had also negative effect on the DT. As the concentration of PG was increased from low level to high level, the DT was found to be increased as in Figure $1(\mathrm{C})$. But increasing concentration of $P G$ had improved the strength of the film making it more acceptable for oral use. Plasticizer act by inserting themselves between the polymer strands and break the polymer-polymer interactions and increases the molecular mobility of the polymer strands [19]. Greater physical strength at higher levels of PG led to higher impart resistance to break the film, resulting in increased DT.

Drug release study was carried out at saliva $\mathrm{pH}$ (6.8) to simulate the condition. The drug release was found to be in the range of 78.25 to $97.56 \%$ as shown in Table 4. The polynomial equation for DR as given in Eq 2.

$\mathrm{Y} 2=+86.87+1.57 \mathrm{~A}+5.20 \mathrm{~B}+1.51 \mathrm{C}+1.48 \mathrm{AC} \ldots$.

The model $F$-value 0.0395 indicates the model is significant $(p<0.05)$. The suggested model for the $\mathrm{Y} 2$ was found to be $2 \mathrm{FI}$ as shown in Table 5. The value of correlation coefficient $\left(R^{2}\right)$ for the response $\mathrm{Y} 2$ was 0.9353 which indicates the good fit for the $2 \mathrm{FI}$ model. The $p$-value for the Y2 model was found to be 0.0395 which clearly indivates the model is statistically significant. Also among the three independent variables selected all factors $\mathrm{A}(p=0.0351), \mathrm{B}(p=0.0098)$, C $(p=0.02865)$. Data shown in Table 6 . Diagnostics case statistics for various response variables are shown in Table 7. Comparative DR profile is given in Figure 2.

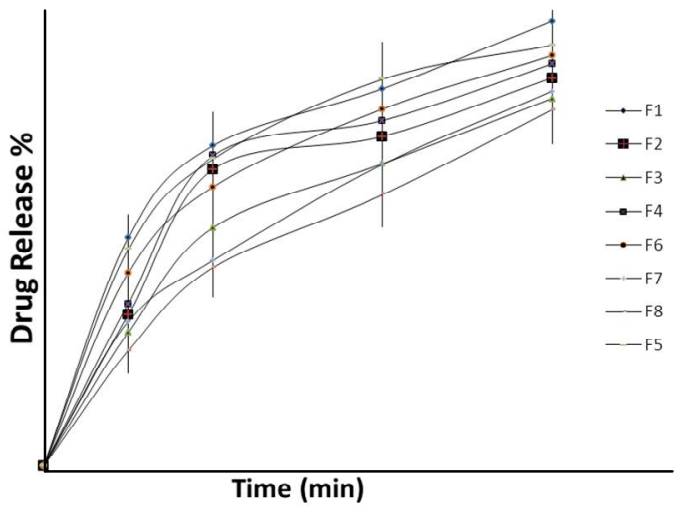

Figure 2: Comparative drug release profile of the films in $6.8 \mathrm{pH}$ phosphate buffer

From the contor plot Figure 1 (D), drug release decreased as the amount of polymer increased from 30 to $40 \%$. As HPMC form a matrix at physiological $\mathrm{pH}$, it retarded the release of the drug from the film. Hence at higher concentration of the polymer, drug release was lower compared to the lower level of polymer concentration. HPMC is the hydrophilic polymer which absorbs the water and forms the gel this gel is responsible for the retardation of the drug from the film system. Hydrophilic polymers create the pore and the channels on the film surface that led to release of the drug from the film [20]. The effect of HPMC on DR was found to be statistically significant. The CCS has also a significant effect on the DR. The effect is shown in Figure 3(A). As discussed above it also has the swelling property.

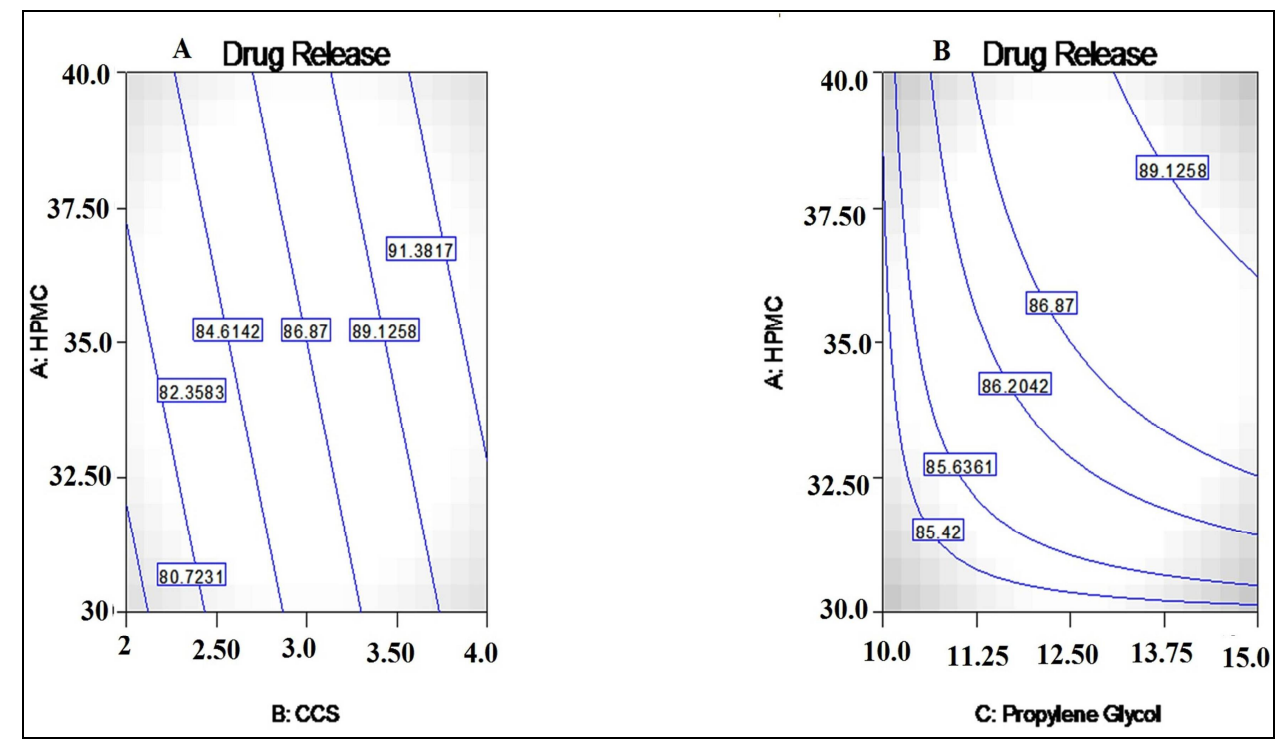

Figure 3: $(A)=$ Effect of CCS on DR from the films; $(B)=$ Effect of PG on DR from the films 
Due to swelling of the film it favored the release from the film. Due to disintegrant property of CCS, it helped to break the film at saliva $\mathrm{pH}$ and that resulted in to the fast release of the LVX from the film. CCS has positive effect on DR as that seen in DT. DR from the film system was also affected by concentration of plasticizer and it had a direct relationship when the concentration of the plasticizer was increased as shown in Figure 3 (B). A positive coefficient in above equation clearly indicates the favourable effect on the DR. LVX oral fast disintegrating films has also been developed with the intention to improve the patient compliance in pediatrics who are suffering from the endocrine disorder hypothyroidism and goiter. These films had great pharmaceutical acceptance in terms of the physical appearance, strength, $\mathrm{pH}$, folding endurance, uniform drug content within films. All selected independent variables had great influence on DT and DR. HPMC being hydrophlic polymer played great role in the development of the LVX films. HPMC imparted good strength to the films and controlled the release from the films. Also CCS was the key excipient in the films to maintain the DT at saliva $\mathrm{pH}$. Its mechanism is already discussed in result part. The effect of CCS was found to be statistically significant in case of both independent factors. The same effect was observed in case of the PG. Definitely these oral fast disintegrating films could be novel technology for the pediatric patients for the management of the hypothyroidism.

\section{CONCLUSION}

Oral fast disintegrating LVX films can be successfully prepared using the HPMC, CCS and $P G$. Such an oral fast disintegrating film is a potentially suitable delivery system for pediatric patients who have swallowing problem of other solid dosage forms, and can thus be used in the management of hypothyroidism in these patients.

\section{REFERENCES}

1. Sarah B D, Ryan S. Hypothyroidism: Causes, Killers, and Life-Saving Treatment. Emer. Med. Clin. North Amer 2014; 32(2): 303-317.

2. Chauhan VK, Manchanda RK, Narang A. Marwaha, RK, Arora S, Nagpal L. Efficacy of homeopathic intervention in subclinical hypothyroidism with or without autoimmune thyroiditis in children: an exploratory randomized control study. Homeopathy 2014; 103 (4): 224-231.

3. Sevil AY, Cahide Y, Avni K, Lokman Ü, Ertan S, Yasar C, Hüseyin C. A case of congenital hypothyroidism presented with dysmyelinization findings. J. Acute Dis 2014; 3(1): 74-76.

4. Vanes NK, Charlesworth D, Imtiaz R, Cox P, Kilby MD, Chan SY. Optimal treatment of hypothyroidism associated with live birth in cases of previous recurrent placental abruption and stillbirth. Int. J. Gynae. Obstr 2013; 123(3): 196-199.

5. Cassio A, Monti S, Rizzello A, Bettocchi I, Baronio F, Addabbo GD. Comparison between Liquid and Tablet Formulations of Levothyroxine in the Initial Treatment of Congenital Hypothyroidism. J. Pedi 2013;162 (6): 12641269.e2

6. Collier JW, Shah RB, Bryant AR, Habib MJ, Khan MA, Faustino PJ. Development and application of a validated HPLC method for the analysis of dissolution samples of levothyroxine sodium drug products. J. Pharm. Biomed. Anal 2011; 54(3): 433-438.

7. Girolamo GD, Keller GA, Santos AR, Schere $D$, Gonzalez $C D$. Bioequivalence of two levothyroxine tablet formulations without and with mathematical adjustment for basal thyroxine levels in healthy Argentinian volunteers: A single-dose, randomized, open-label, crossover study. Clin Ther 2008; 30(11): 2015-2023.

8. Stoltenberg I, Breitkreutz J. Orally disintegrating minitablets (ODMTs) A novel solid oral dosage form for pediatric use. Euro. J. Pharm Biopharm 2011; 78(3): 462-469.

9. Batchelor $H K$, Kendall $R$, Brethes $S D$, Alex R, Ernest $T$ $B$. Application of in vitro biopharmaceutical methods in development of immediate release oral dosage forms intended for pediatric patients. Euro. J. Pharm and Biopharm. 2013; 85(3): Part B 833-842.

10. Chaudhary H, Gauri S, Rathee P, Kumar V. Development and optimization of fast dissolving oro-dispersible films of granisetron $\mathrm{HCl}$ using Box-Behnken statistical design. Bull. Faculty Pharm, Cairo University. 2013; 51(2): 193-201.

11. Dinge A. Nagarsenker M. Formulation and evaluation of fast dissolving films for delivery of triclosan to the oral cavity. AAPS PharmSciTech. 2008; 9: 349-356.

12. Muzib YI, Kumari KS. Mucoadhesive buccal films of glibenclamide: Development and evaluation. Int. J. Pharma. Investig. 2011; 1:42-47.

13. Sapkal NP, Kilor VA, Daud AS, Bonde MN. Development of fast dissolving oral thin films of ambroxol hydrochloride: effect of formulation variables. J. Adv. Pharm. Res. 2011;2:102-109.

14. Walsh J, Mills S. Formulating better medicines for children: 4th European Paediatric Formulation Initiative Conference. Ther Deliv 2013; 4: 21-25.

15. Nagaraju T, Gowthami R, Rajashekar M. Comprehensive review on oral disintegrating films. Curr Drug Deliv 2012; 3:30-45.

16. Yasser EM, Sami N. Hydrophilic matrices: Application of Placket-Burman screening design to model the effect of POLYOX-carbopol blends on drug release. Int. J. Pharm 2006; 309(1-2): 163-170. 
17. Nishimura $M$, Matsuura $K$, Tsukioka K, Yamashita $H$, Inagaki $N$, Sugiyama $T$, Itoh $Y$ In vitro and in vivo characteristics of prochlorperazine oral disintegrating film. Int. J. Pharm 2009; 368:98-102.

18. Dahiya M, Saha S, Shahiwala A. A review on mouth dissolving film. Curr. Drug Deliv 2009; 6(5): 469-476.

19. Dixit AS, Kulkarni PK. Fast Disintegrating Films Containing Anastrozole as a Dosage Form for
Dysphagia Patients. Arch Pharm Res 2012; 35(12):2171-2182.

20. Giacoia GP, Taylor ZP, Zajicek A. Eunice Kennedy Shriver National Institute of Child Health and Human Development Pediatrics Formulation Initiative: proceedings from the second workshop on pediatric formulations. Clin Ther 2012; 34(Suppl.): S1-S10. 